\title{
Human cathelicidin LL-37-derived peptide IG-19 confers protection in a murine model of collagen-induced arthritis
}

\author{
Leola N.Y. Chow ${ }^{\mathrm{a}, 1}$, Ka-Yee (Grace) Choi ${ }^{\mathrm{a}, \mathrm{b}, 1}$, Hadeesha Piyadasa ${ }^{\mathrm{a}, \mathrm{b}}$, Maike Bossert ${ }^{\mathrm{c}}$, \\ Jude Uzonna $^{\mathrm{b}}$, Thomas Klonisch ${ }^{\mathrm{c}}$, Neeloffer Mookherjee ${ }^{\mathrm{a}, \mathrm{b}, *}$ \\ ${ }^{a}$ Manitoba Centre for Proteomics and Systems Biology, Department of Internal Medicine, University of Manitoba, Winnipeg, MB, R3E 3P4, Canada \\ ${ }^{\mathrm{b}}$ Department of Immunology, University of Manitoba, Winnipeg, MB, R3E 3P4, Canada \\ ${ }^{\mathrm{c}}$ Department of Human Anatomy and Cell Science, University of Manitoba, Winnipeg, MB, R3E 3P4, Canada
}

\section{A R T I C L E I N F O}

\section{Article history:}

Received 11 July 2013

Received in revised form 7 August 2013

Accepted 12 August 2013

Available online 1 October 2013

\section{Keywords:}

Rheumatoid arthritis

Chronic inflammation

Collagen-induced arthritis

Host defence peptides

Cathelicidin

LL-37

\begin{abstract}
A B S T R A C T
Current therapies for autoimmune chronic inflammatory diseases e.g. rheumatoid arthritis (RA) include inhibitors of inflammatory cytokines. However, these therapies can result in increased risk of infections. There is a need to explore alternate strategies that can control inflammation without compromising the innate ability to resolve infections. In this study, we examined the effect of small peptides derived from endogenous cathelicidin peptides in a murine model of collagen-induced arthritis (CIA). Cathelicidins are immunomodulatory peptides known to control infections. We demonstrate that the administration of the peptide IG-19, which represents an internal segment of the human cathelicidin LL-37, decreased disease severity and significantly reduced the serum levels of antibodies against collagen type II in the CIA model. IG-19 peptide reduced cellular infiltration in joints, prevented cartilage degradation and suppressed proinflammatory cytokines in the CIA mice. We also showed that not all cathelicidin-derived peptides exhibit similar functions. A bovine cathelicidin-derived peptide IDR-1018 did not exhibit the beneficial effects observed with the human cathelicidin LL-37-derived peptide IG-19, in the same murine model of CIA. This is the first study to provide evidence demonstrating the ability of a peptide derived from the human cathelicidin LL-37 to alleviate the arthritic disease process in a murine model of RA. Our results has lead us to propose a new approach for controlling autoimmune chronic inflammatory disorders such as RA, by using specific synthetic derivatives of endogenous host defence peptides. Cathelicidin-derived peptides are particularly attractive for their dual antimicrobial and anti-inflammatory actions.
\end{abstract}

(c) 2013 Elsevier Ltd. All rights reserved.

\section{Introduction}

Rheumatoid arthritis (RA) is an autoimmune chronic inflammatory disease known to affect approximately $1 \%$ of the population worldwide (Gabriel, 2001). Current treatments for RA include inhibitors of inflammatory cytokines such as TNF- $\alpha$ (Asquith and Mclnnes, 2007; Feldman and Maini, 2003; Gartlehner et al., 2006). Although effective, a significant drawback is a compromised immune system resulting in increased risks of infections and tumor development, as inflammatory cytokines also play a critical role in host defence mechanisms (Winthrop, 2006; Botsios, 2005). This highlights the importance of exploring alternate therapeutic approaches with the potential to control the disease process in

\footnotetext{
* Corresponding author at: Rm 799 John Buhler Research Centre, 715 McDermot Avenue, Winnipeg, MB, R3E 3P4, Canada. Tel.: +1 204272 3115; fax: +1 2044801362 .

E-mail address: Neeloffer.Mookherjee@med.umanitoba.ca (N. Mookherjee).

1 These authors contributed equally.
}

inflammatory arthritis without compromising the innate ability to resolve infections.

Endogenous host defence peptides (HDPs) are known to contribute to the resolution of both infections and inflammation (Bowdish et al., 2005; Jo, 2010; Nizet et al., 2001; Kanda et al., 2010; Dombrowski et al., 2011). Two best characterized families of HDPs in mammals are cathelicidins and defensins. The sole human cathelicidin is a 37-amino acid peptide known as LL-37 (Burton and Steel, 2009). The human cathelicidin LL-37 plays a critical role in maintaining the balance between pro- and antiinflammatory responses in immune homeostasis (reviewed in (Choi and Mookherjee, 2012; Vandamme et al., 2012)). We have previously shown that LL-37 alters endotoxin-induced Toll-like receptor-to-NFKB signaling mechanisms and significantly suppress the production of inflammatory cytokines without altering certain chemokine responses required for immune cell recruitment to the site of infection (Mookherjee et al., 2006a, 2006b). Consistent with this, LL-37 was shown to confer protection in animal models of pathogenic sepsis (Cirioni et al., 2006; Torossian et al., 2007). Moreover, murine cathelicidin knockout models exhibit increased 
susceptibility to infections (Nizet et al., 2001; Chromek et al., 2006) and have increased allergic inflammation (Morioka et al., 2008). A recent study has shown that cathelicidin peptide in mice confer protection in inflammatory colitis (Tai et al., 2007). The role of mammalian cathelicidin peptides in autoimmune chronic inflammatory diseases remains to be elucidated.

Previous studies have demonstrated that smaller peptides derived from cathelicidins, known as innate defence regulator(IDR) peptides, exhibit improved immune-modulatory properties and reduced cytotoxicity compared to the parent HDPs (Scott et al., 2007; Nijnik et al., 2010; Achtman et al., 2012; Molhoek et al., 2009). Therefore, to delineate the effect of cathelicidin-derived peptides in autoimmune chronic inflammatory diseases, we examined the effect of two synthetic immunomodulatory peptides in the collagen-induced arthritis (CIA) murine model. The two peptides used in this study were; (i) a 19-amino acid peptide IG-19, which represents an internal sequence of the human cathelicidin LL-37 (amino acid 13-31) and shown to be the minimal region required for the immunomodulatory functions mediated by LL-37 (Molhoek et al., 2009), and (ii) a bovine cathelicidinderived 12-amino acid peptide IDR-1018, which was previously shown to be protective in murine models of infectious challenge and exhibit immunomodulatory properties (Achtman et al., 2012; Mayer et al., 2013; Wieczorek et al., 2010; Pena et al., 2013). The CIA model is a pre-clinical model of human RA, eliciting autoimmunity to collagen type II (CII) resulting in inflammation of synovial joints, cartilage destruction and bone erosion (Cho et al., 2007). In this study, we demonstrated that administration of the peptide IG-19 decreased disease severity and significantly reduced circulating serum levels of antibodies against the immunizing heterologous chicken $\mathrm{CII}$ and autoantibodies to murine $\mathrm{CI}$ in the CIA mice, whereas the peptide IDR-1018 did not. We also showed that the peptide IG-19 reduced cellular infiltration and prevented proteoglycan depletion or cartilage degradation in the joints of the CIA mice. Administration of the peptide reduced serum concentration of pro-inflammatory cytokines in the CIA mice. This is the first study to demonstrate the beneficial effects of a human cathelicidin LL-37-derived peptide in a murine model of RA.

\section{Material and methods}

\subsection{Collagen-induced arthritis (CIA) murine model}

Highly susceptible male DBA/1J mice ( $~ 6-7$ weeks old) obtained from Jackson laboratories were challenged with a subcutaneous (s.c.) injection of $100 \mu \mathrm{g}$ of chicken CII obtained from Chondrex Inc., emulsified in complete Freund's adjuvant, $1-2 \mathrm{~cm}$ from the base of the tail, followed by a boost on day 21 with chicken CII emulsified in incomplete adjuvant (Brand et al., 2007; Bevaart et al., 2010). The peptides IG-19 (IGKEFKRIVQRIKDFLRNL-NH ${ }_{2}$ ) and IDR1018 (VRLIVAVRIWRR-NH ${ }_{2}$ ) were obtained from CPC Scientific (CA, USA), re-suspended in sterile saline before administration. The peptides were administered at $6 \mathrm{mg} / \mathrm{kg}$ per mouse by s.c. injections from day 20 (one day before boost) onwards and subsequently every $48 \mathrm{~h}$. The mice were sacrificed 8 weeks after initial CII challenge. All murine experimental procedures were approved by the University of Manitoba Animal Care Ethics Board. Disease progression was monitored by measuring joint thickness using digital calipers (Tresna Corporation) every $48 \mathrm{~h}$ from day 22 onwards as previously described (Hutamekalin et al., 2009; Nandakumar and Holmdahl, 2005; Galligan et al., 2010) and the disease severity was assessed using a standardized clinical score (Galligan et al., 2010) in a blinded manner.

\subsection{ELISA and flow cytometry}

Blood was collected by cardiac puncture on the day of sacrifice, serum obtained, aliquoted and stored in $-20^{\circ} \mathrm{C}$ until use. Serum levels of anti-chicken CII antibody and anti-mouse CII antibody were monitored by ELISA (Chondrex Inc., Redmond, WA, USA) as per the manufacturer's recommendation. The production of murine cytokines were analyzed in serum using the multiplex $\mathrm{BD}^{\mathrm{TM}} \mathrm{CBA}$ preconfigured Th1/Th2/Th17 cytokines kit (IL-2, IL-4, IL-6, IFN- $\gamma$, TNF- $\alpha$, IL-17A, IL-10) employing the FACS Calibur ${ }^{\text {TM }}$ flow cytometer (BD Biosciences, Mississauga, ON, Canada) as per manufacturer's instructions and as previously described by us (Turner-Brannen et al., 2011).

\subsection{Histology}

On the day of sacrifice, the ankle joints were collected and fixed in $10 \%$ buffered formalin, decalcified using 10\% EDTA for 14 days followed by dehydration in increasing ethanol concentrations. The tissues were embedded in paraffin and $5 \mu \mathrm{m}$ sagittal serial sections were obtained. The sections were analyzed using hematoxylin and eosin (H \& E) staining to evaluate cellular infiltration. Safranin O stain was used to determine the loss of proteoglycans indicating cartilage degradation. The images were processed using a Zeiss imager M2 using the Zen 2011 software. The stained sections were scored quantitatively as previously described in a blinded manner (van Holten et al., 2004). The extent of infiltration and arthritis was evaluated using a previously published scoring system, where $0=$ normal synovium, $1=$ synovial membrane hypertrophy and cell infiltration, 2 = pannus formation and cartilage erosion, 3 = major erosion of the cartilage, and $4=$ loss of joint integrity (Sun et al., 2011; Nishikawa et al., 2003).

\subsection{Statistical analysis}

Independent $t$-tests for unequal variance was used to determine statistical significance. The trend for the number of affected limbs over time was analyzed using the Tukey HSD test. A $p$-value of $<0.05$ was considered to be statistically significant.

\section{Results}

\subsection{Peptide IG-19 reduces disease severity in the CIA mice}

The CIA model exhibits pathological and immunological characteristics similar to human RA and is widely used as a pre-clinical model for RA (Cho et al., 2007; Brand et al., 2007; Bevaart et al., 2010; Hegen et al., 2008). In this study, we examined the effect of the cathelicidin-derived peptides IG-19 and IDR-1018 in the collagen-induced arthritis (CIA) murine model. Previous pre-clinical studies that employed cathelicidin-derived peptides in murine models have used anywhere between $1 \mathrm{mg} / \mathrm{kg}$ and $24 \mathrm{mg} / \mathrm{kg}$ of the peptides per mouse (Scott et al., 2007; Nijnik et al., 2010; Achtman et al., 2012). Keeping at the lower range, the peptides were administered at $6 \mathrm{mg} / \mathrm{kg}$ per mouse. The mice with the peptide injections (for 5 weeks every $48 \mathrm{~h}$ ) did not show any signs of physical distress such as either ruffled fur, lack of active movement in cage or obvious discomfort in gait. Administration of both the peptides significantly reduced the number of affected limbs in the CIA mice, with peptide IG-19 having a more robust impact compared to the peptide IDR-1018 (Fig. 1A). Moreover, peptide IG-19 markedly reduced the disease severity as assessed by total clinical score (Galligan et al., 2010) on the day of sacrifice, whereas the peptide IDR-1018 did not (Fig. 1B). Even though a small number of CIA mice developed arthritic symptoms with IG-19 
A.

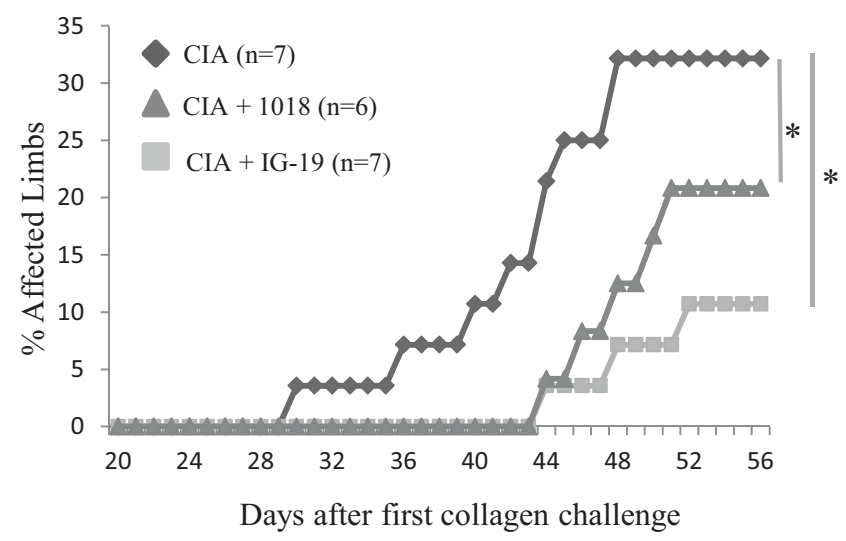

B.

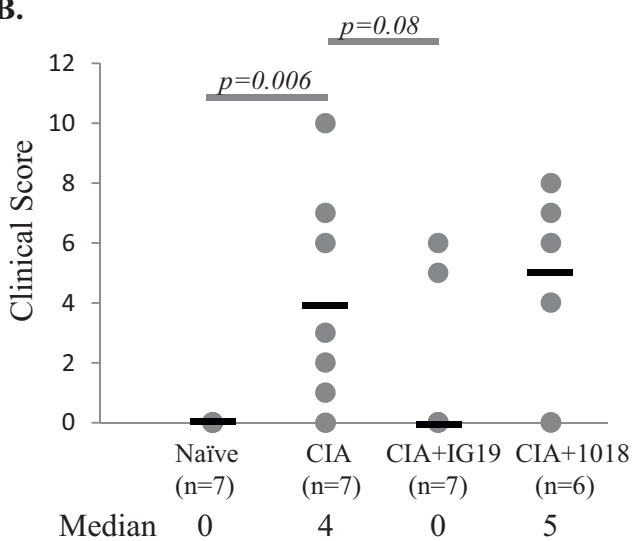

Fig. 1. Peptide IG-19 reduces disease severity in the CIA mice. DBA/1 mice were challenged with type II chicken collagen, and the peptides IG-19 or IDR-1018 were administered by s.c. injections from day 20 onwards every $48 \mathrm{~h}$. Mice were sacrificed 8 weeks after initial collagen challenge. (A) Joint thickness was measured by a digital caliper to assess progression of affected limbs from day 20 onwards. Statistical significance for the trend of the number of affected limbs over time was analyzed using the Tukey HSD test $\left({ }^{*} p<0.05\right)$. (B) Total clinical score was evaluated on the day of the sacrifice.

administrations ( 2 out of 7 mice), the onset of disease was delayed in these mice (Fig. 1A). The median clinical score of CIA mice administered with the peptide IG-19 was zero, similar to that seen with naïve and peptide alone group (Fig. 1B). These results suggested that the peptide IG-19 has the potential to control disease progression and reduce disease severity in inflammatory arthritis.

\subsection{Peptide IG-19 significantly reduces production of anti-collagen type II (CII) antibodies in the CIA mice}

CII is exclusively expressed in articular cartilage of the joints and is considered an autoantigen in the CIA animal model (Cho et al., 2007). In the CIA model, immunization of the susceptible DBA/ $1 \mathrm{~J}$ mice with heterologous chicken CII results in the production of antibodies to the immunizing heterologous CII antigen, as well as the production of murine CII-specific autoantibodies. Therefore, in this study we monitored the circulating serum concentrations of antibodies to the chicken CII (immunizing antigen) and to murine CII (autoantigen) by ELISA. We demonstrated that CIA mice had significantly elevated levels of both anti-chicken and anti-mouse CII antibodies (Fig. 2). Concentrations of serum anti-CII antibodies were significantly reduced by the administration of the peptide IG-19, but not with peptide IDR-1018 (Fig. 2). Administration of the peptide IG-19 reduced serum concentration of anti-chicken CII antibodies by $>35 \%, p=0.013$ (Fig. 2A) and anti-mouse CII
A. Anti-chicken collagen antibody
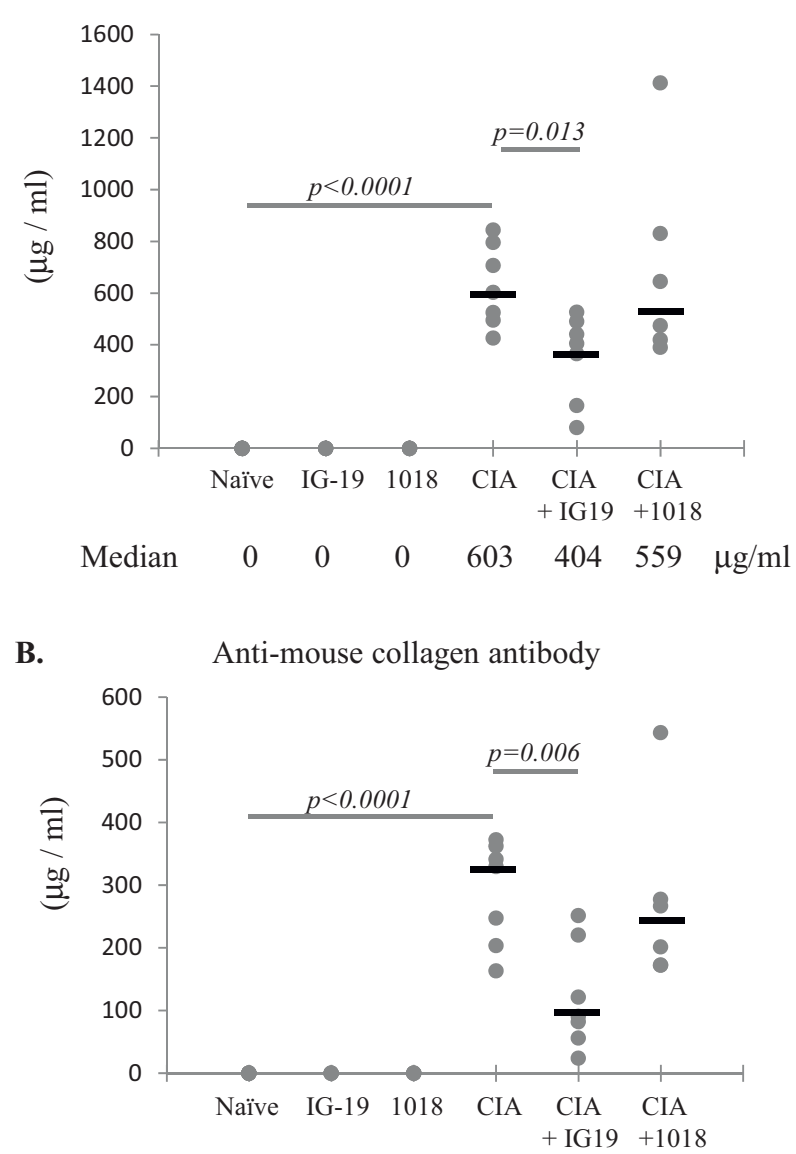

Median $\quad \begin{array}{lllllll}0 & 0 & 0 & 330 & 105 & 234 & \mu \mathrm{g} / \mathrm{ml}\end{array}$

Fig. 2. Peptide IG-19 significantly reduces serum concentration of collagen type II antibodies in the CIA mice. DBA/1 mice were challenged with type II chicken collagen, and the peptides IG-19 or IDR-1018 were administered by s.c. injections from day 20 onwards every $48 \mathrm{~h}$. Mice were sacrificed 8 weeks after initial collagen challenge. The concentrations of (A) anti-chicken collagen type II antibodies and (B) anti-mouse collagen type II antibodies were monitored in the serum obtained on the day of sacrifice by ELISA. Independent $t$-tests for unequal variance was used to determine p-values.

autoantibodies by $70 \%, p=0.006$ (Fig. 2B), in the CIA mice on the day of sacrifice.

\subsection{Peptide IG-19 alters serum cytokines in the CIA mice}

As the peptide IG-19 significantly reduced diseases severity (Fig. 1) and the levels of serum CII antibodies (Fig. 2), we further monitored the effect of the peptide IG-19 on serum concentrations of a panel of Th1/Th2/Th17 cytokines (IL-2, IL-4, IL-6, IFN- $\gamma$, TNF- $\alpha$, IL-17A, IL-10) by multiplex flow cytometry. Administration of the peptide IG-19 alone did not significantly increase the serum concentration of any of the cytokines monitored (IL-2, IL-4, IL-6, IFN- $\gamma$, TNF- $\alpha$, IL-10 and IL-17). However, the serum concentration of the cytokine IL-10 was increased by 1.7 -fold in mice administered with IG-19 alone compared to naïve, but this increase was not statistically significant (Fig. 3). The CIA mice had significantly increased serum concentrations of TNF- $\alpha$, IFN- $\gamma$ and IL- 6 between $2-$ and $3-$ fold $(p<0.05)$ compared to the naïve mice on the day of sacrifice (Fig. 3). Administration of the peptide IG-19 significantly reduced the serum concentrations of pro-inflammatory cytokine TNF- $\alpha$ by more than $60 \%(p=0.003)$ and that of the cytokine IL-10 by $50 \%$ $(p=0.02)$, in the CIA mice (Fig. 3 ). Likewise, the CIA mice showed 


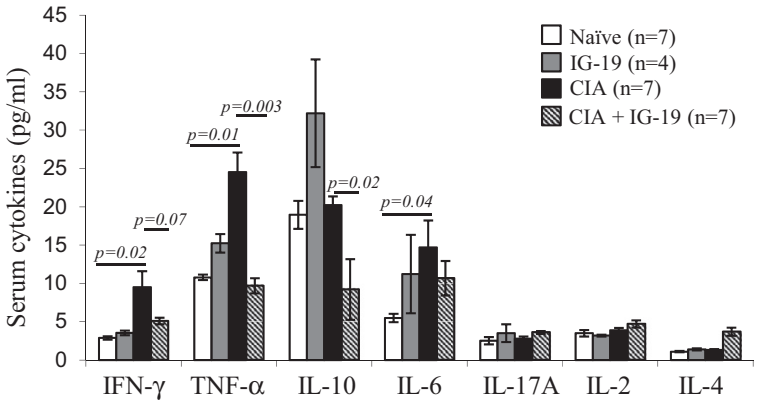

Fig. 3. Peptide IG-19 alters serum concentrations of cytokines. DBA/1 mice were challenged with type II chicken collagen, and the peptides IG-19 or IDR-1018 were administered by s.c. injections from day 20 onwards every $48 \mathrm{~h}$. Mice were sacrificed 8 weeks after initial collagen challenge. Circulating levels of a panel of Th1/Th2/Th17 cytokines (IL-2, IL-4, IL-6, IFN- $\gamma$, TNF- $\alpha$, IL-17A, IL-10) were monitored in the serum collected on the day of sacrifice using multiplex $\mathrm{BD}^{\mathrm{TM}} \mathrm{CBA}$ preconfigured kit employing the FACS Calibur ${ }^{\mathrm{TM}}$ flow cytometer. Results shown represent average \pm standard error. Independent $\mathrm{T}$-tests for unequal variance was used to determine the p-values.
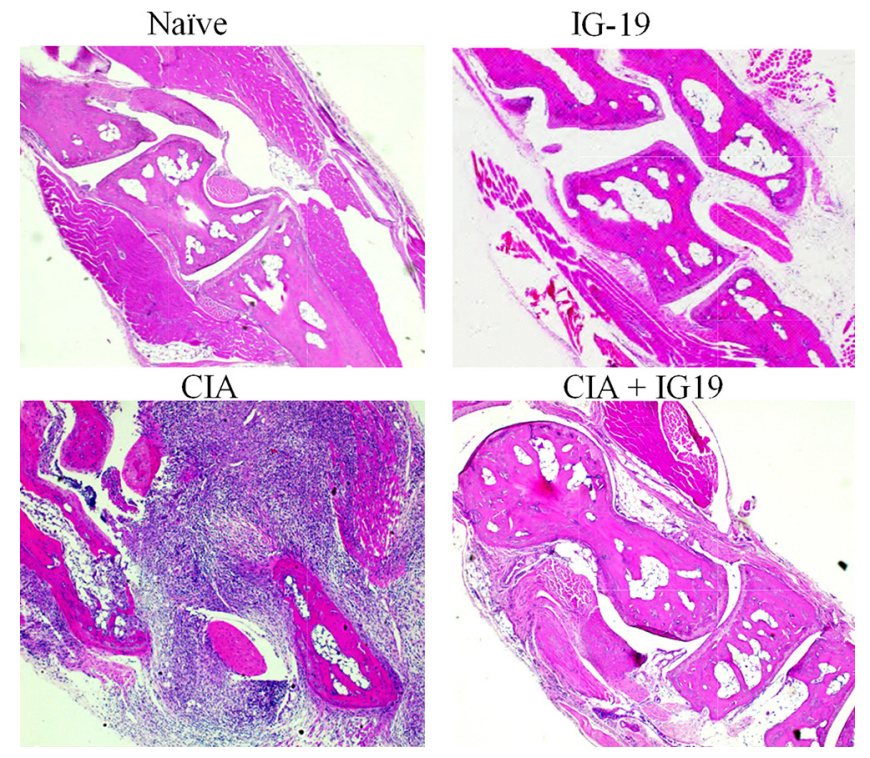

Fig. 4. Peptide IG-19 reduces cellular infiltration in the joints of the CIA mice. The paraffin embedded sagittal sections $(5 \mu \mathrm{m})$ of hind ankle joints obtained on the day of sacrifice were stained with $\mathrm{H} \& \mathrm{E}$. Images shown are representative of sections from naïve $(n=7)$, CIA $(n=7)$, IG-19 $(n=4)$ and CIA + IG-19 $(n=7)$. The images were processed using a Zeiss imager M2 using the Zen 2011 software.

a solid trend of suppression of serum concentration of IFN- $\gamma$ more than $40 \%$ ( $p=0.07)$ with administration of the peptide IG-19 (Fig. 3).

\subsection{Peptide IG-19 prevents cellular influx and cartilage degradation in the joints of CIA mice}

Histopathological assessment of paraffin embedded sagittal sections of ankle joints with $\mathrm{H} \& \mathrm{E}$ stain indicated that administration of the peptide IG-19 reduced cellular infiltration in the CIA mice (Fig. 4). Staining the sections for proteoglycans by Safranin O for the detection of cartilage revealed that the CIA mice had significant proteoglycan depletion indicating cartilage degradation (Fig. 5). CIA mice showed erosion of cartilage, pannus formation (Fig. 5C) to a complete loss of joint integrity (Fig. 5D). In contrast, administration of the peptide IG-19 inhibited proteoglycan depletion and maintained integrity of the joint in CIA mice (Fig. 5E). None of the CIA mice treated with peptide IG-19 showed complete loss of joint integrity. While the CIA mouse with a clinical score of 6 displayed complete loss of joint integrity (Fig. 5D), this was not the case with the outlier CIA mouse administered with the peptide IG-19. Despite showing arthritic symptoms with a clinical score of 6 (Fig. 1B), this CIA mouse with peptide IG-19 failed to display a complete loss of joint integrity (Fig. 5F). To account for the variability in the different groups, we further scored the stained sections by two independent observers in a blinded manner. The histology score demonstrated that administration of the peptide IG-19 significantly reduced cellular infiltration and protected against cartilage degradation in the CIA mice (Fig. 6).

\section{Discussion}

In this study, we demonstrated that a synthetic derivative of the human cathelicidin LL-37, peptide IG-19, alleviates arthritic symptoms in a murine model of CIA. The disease severity as indicated by a standardized clinical score (Galligan et al., 2010) and the number of affected limbs were markedly reduced in the CIA mice administered with the peptide IG-19 (Fig. 1). Histological assessment demonstrated that administration of the peptide IG-19 significantly reduced cellular infiltration and prevented cartilage degradation in the joints of the CIA mice (Figs. 4-6). Moreover, in this study we showed that the peptide IG-19 significantly suppressed the serum levels of CII antibodies, both to the immunizing chicken CII antigen and to the murine CII autoantigen, in the CIA mice (Fig. 2). The incidence of CIA had been shown to correlate with the serum levels of anti-collagen antibodies (Holmdahl et al., 1986). Our results suggest that the peptide IG-19 when given one day before the boost may alter immune regulation during progression of inflammatory arthritis and consequently suppresses the production of autoantibodies to CII. Future work will determine if the peptide IG19 can alleviate the disease once arthritic symptoms have developed. This is the first study to establish the proof-ofprinciple for the beneficial effects of a LL-37-derivative peptide IG-19 in immune-mediated chronic inflammatory disorders, such as autoimmune chronic inflammatory RA.

The peptide IG-19 effectively suppressed pro-inflammatory cytokine levels, in particular concentration of TNF- $\alpha$, in the serum of the CIA mice (Fig. 3). The pro-inflammatory cytokine TNF- $\alpha$ is known to intensify the disease severity in CIA (Brahn et al., 1992; Cooper et al., 1992) and the level of TNF- $\alpha$ directly correlates with disease severity in RA patients (Altomonte et al., 1992). TNF- $\alpha$ stimulates collagenase which disrupts the extracellular collagen matrix in inflamed joints, and increases prostaglandin E2 which triggers bone reabsorption by osteoclasts (Dayer et al., 1985; Saklatvala, 1986). The ability of IG-19 to significantly reduce serum concentration of TNF- $\alpha$ suggests that the peptide can control the disease progression in the CIA model. This is also supported by the observed solid trend of suppression of serum levels of IFN- $\gamma$ by the peptide treatment in the CIA mice (Fig. 3). While the peptide IG-19 alone did not significantly increase the circulating levels of any of the cytokines monitored, a trend of up-regulation of IL-10 was observed (Fig. 3). We have shown in a previous study that the parent HDP LL-37 induces intracellular production of IL-10 (Mookherjee et al., 2009). However, other studies have demonstrated an inverse correlation of HDP LL-37 with IL-10 (Kanda et al., 2010; van der Does et al., 2010). Interestingly, in this study the peptide IG-19 significantly reduced serum IL-10 in the CIA mice (Fig. 3). It may be possible that IL-10 is counter balanced by the pro-inflammatory cytokines such as TNF- $\alpha$ and IFN- $\gamma$, which are known to exacerbate disease severity in the CIA model (Brahn et al., 1992; Cooper et al., 1992, 1988). It is also possible that the anti-inflammatory effects of the peptide IG-19 may be independent of IL-10 production. This is consistent with the fact that the therapeutic potential of IL-10 for chronic inflammatory autoimmune diseases is yet to be fully established (Iyer and Cheng, 2012). 
A.

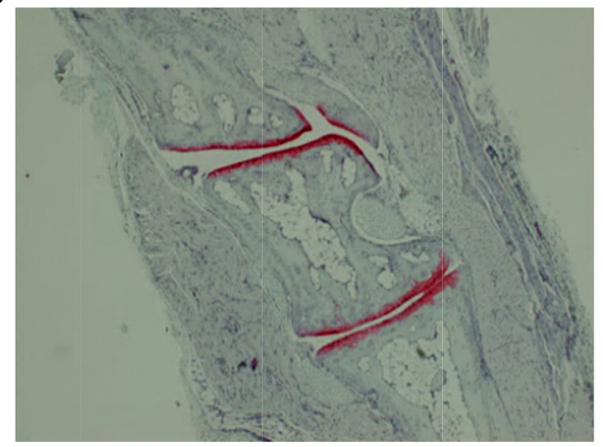

C.

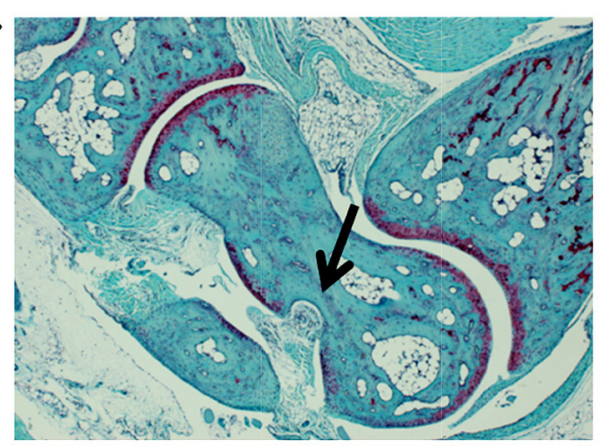

B.

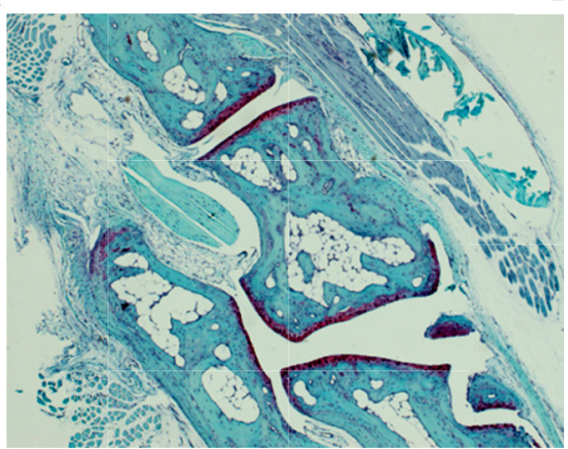

D.

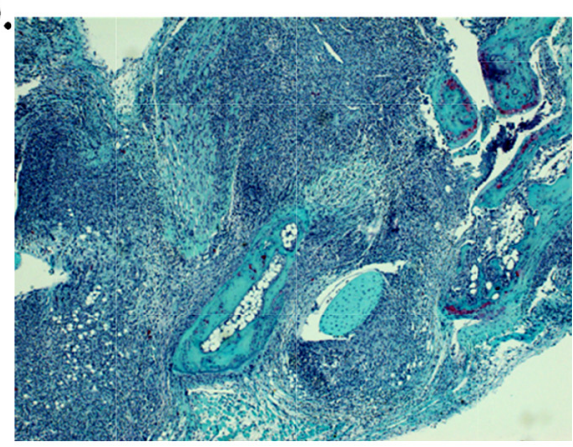

E.

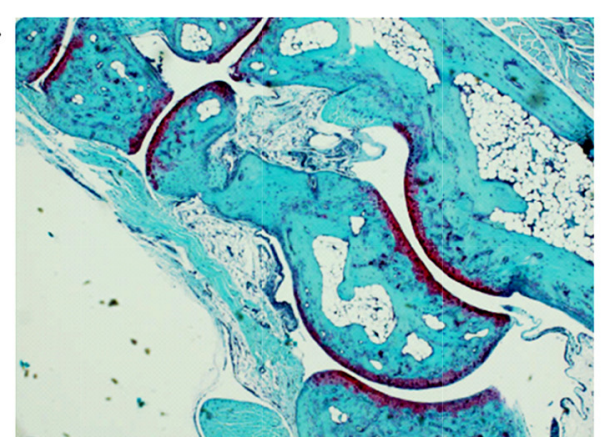

F.

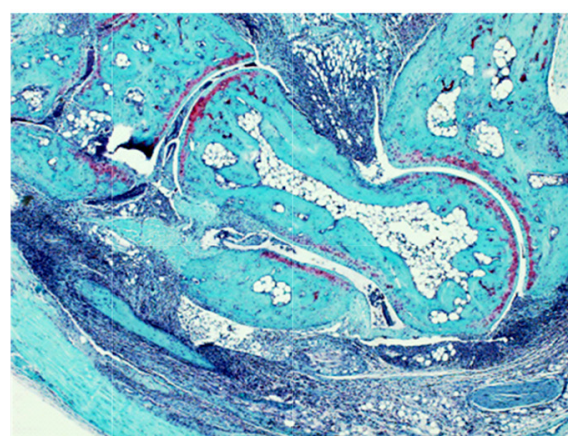

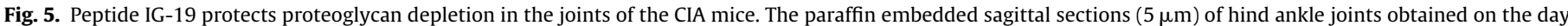

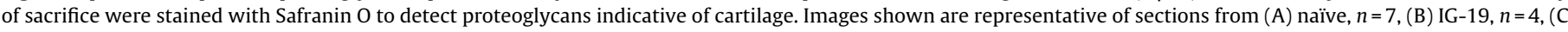

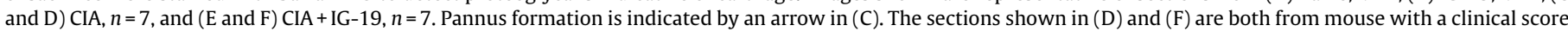
of 6 . The images were processed using a Zeiss imager M2 using the Zen 2011 software.

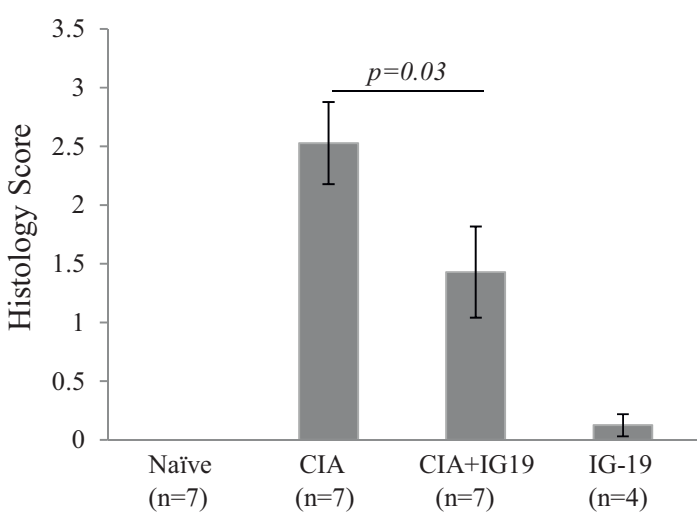

Fig. 6. Peptide IG-19 significantly reduces cell infiltrates and tissue damage in the CIA mice. The paraffin embedded sagittal sections $(5 \mu \mathrm{m})$ of hind ankle joints obtained on the day of sacrifice were stained with $\mathrm{H} \& \mathrm{E}$ and Safrinin O. The stained sections were scored using a standardized histology score as indicated in Section 2 , to assess the extent of cell infiltrates and tissue damage. Independent $t$-tests for unequal variance was used to determine the $p$-values.
Overall, this study provides novel evidence demonstrating the ability of a human cathelicidin LL-37-derived peptide to alleviate the disease process in a murine model of RA. We also show that not all cathelicidin-derived peptides exhibit similar functions. The bovine cathelicidin-derived peptide IDR-1018 did not exhibit the beneficial effects seen with the human cathelicidin-derived peptide IG-19 in the murine model of CIA (Figs. 1 and 2). The structure-function relationship of cathelicidin-derived peptides in the context of modulating immune-mediated inflammation is yet to be determined. Nevertheless, this study suggests a new approach for controlling autoimmune chronic inflammatory disorders such as RA, using specific peptide derivatives of endogenous HDPs. The safety of HDP-derived peptides for clinical use in humans has been established, as some of these peptides are currently in phase II/III clinical trials (Yeung et al., 2011). The manufacturing cost can be reduced with shorter peptides (Scott et al., 2007; Nijnik et al., 2010; Cherkasov et al., 2009) and new recombinant methods (Bommarius et al., 2010). A major advantage of developing small synthetic derivatives of HDPs as therapeutics for chronic inflammatory disorders is their unique dual potential to control inflammation and resolve infections (Choi and Mookherjee, 2012; Scott et al., 2007; 
Turner-Brannen et al., 2011), which is distinct from the current biologics used for the treatment of RA and other chronic inflammatory diseases.

\section{Conflict of interest}

\section{The authors declare no conflict of interest.}

\section{Acknowledgements}

The authors very much appreciate intellectual input from Drs. Eleanor Fish and Hani El-Gabalawy for this study. Funding support for this study was obtained from the Manitoba Health Research Council (MHRC) and the Health Sciences Center Foundation, Manitoba, Canada. KGC is supported by a studentship from MHRC.

\section{References}

Achtman, A.H., Pilat, S., Law, C.W., Lynn, D.J., Janot, L., Mayer, M.L., Ma, S., Kindrachuk, J., Finlay, B.B., Brinkman, F.S., et al., 2012. Effective adjunctive therapy by an innate defense regulatory Peptide in a preclinical model of severe malaria. Science Translational Medicine 4, 135 ra64.

Altomonte, L., Zoli, A., Mirone, L., Scolieri, P., Magaro, M., 1992. Serum levels of interleukin-1b, tumor necrosis factor-a and interleukin-2 in rheumatoid arthritis correlation with disease activity. Clinical Rheumatology 11, 202-205.

Asquith, D.L., Mclnnes, I.B., 2007. Emerging cytokine targets in rheumatoid arthritis. Current Opinion in Rheumatology 19, 246-251.

Bevaart, L., Vervoordeldonk, M.J., Tak, P.P., 2010. Collagen-induced arthritis in mice Methods in Molecular Biology 602, 181-192.

Bommarius, B., Jenssen, H., Elliott, M., Kindrachuk, J., Pasupuleti, M., Gieren, H. Jaeger, K.E., Hancock, R.E., Kalman, D., 2010. Cost-effective expression and purification of antimicrobial and host defense peptides in Escherichia coli. Peptides 31, 1957-1965.

Botsios, C., 2005. Safety of tumour necrosis factor and interleukin-1 blocking agents in rheumatic diseases. Autoimmunity Reviews 4, 162-170.

Bowdish, D.M., Davidson, D.J., Lau, Y.E., Lee, K., Scott, M.G., Hancock, R.E., 2005. Impact of LL-37 on anti-infective immunity. Journal of Leukocyte Biology 77, 451-459.

Brahn, E., Peacock, D.J., Banquerigo, M.L., Liu, D.Y., 1992. Effects of tumor necrosis factor alpha (TNF-alpha) on collagen arthritis. Lymphokine Cytokine Research $11,253-256$.

Brand, D.D., Latham, K.A., Rosloniec, E.F., 2007. Collagen-induced arthritis. Nature Protocols 2, 1269-1275.

Burton, M.F., Steel, P.G., 2009. The chemistry and biology of LL-37. Natural Products Reports 26, 1572-1584.

Cherkasov, A., Hilpert, K., Jenssen, H., Fjell, C.D., Waldbrook, M., Mullaly, S.C., Volkmer, R., Hancock, R.E., 2009. Use of artificial intelligence in the design of small peptide antibiotics effective against a broad spectrum of highly antibioticresistant superbugs. ACS Chemical Biology 4, 65-74

Cho, Y.G., Cho, M.L., Min, S.Y., Kim, H.Y., 2007. Type II collagen autoimmunity in a mouse model of human rheumatoid arthritis. Autoimmunity Reviews 7, 65-70.

Choi, K.Y., Mookherjee, N., 2012. Multiple immune-modulatory functions of cathelicidin host defense peptides. Frontiers in Immunology 3, 149.

Chromek, M., Slamova, Z., Bergman, P., Kovacs, L., Podracka, L., Ehren, I., Hokfelt, T., Gudmundsson, G.H., Gallo, R.L., Agerberth, B., et al., 2006. The antimicrobial peptide cathelicidin protects the urinary tract against invasive bacterial infection. Nature Medicine 12, 636-641.

Cirioni, O., Giacometti, A., Ghiselli, R., Bergnach, C., Orlando, F., Silvestri, C., Mocchegiani, F., Licci, A., Skerlavaj, B., Rocchi, M., et al., 2006. LL-37 protects rats against lethal sepsis caused by gram-negative bacteria. Antimicrobial Agents and Chemotherapy 50, 1672-1679.

Cooper, S.M., Sriram, S., Ranges, G.E., 1988. Suppression of murine collagen-induced arthritis with monoclonal anti-Ia antibodies and augmentation with IFN- $\alpha^{1}$. The Journal of Immunology 141, 1958-1962.

Cooper, W.O., Fava, R.A., Gate, C.A., Cremer, M.A., Townes, A.S., 1992. Acceleration of onset of collagen-induced arthritis by intra-articular injection of tumour necrosis factor or transforming growth factor-beta. Clinical Experimental Immunology 89, 244-250.

Dayer, J.M., Beutler, B., Cerami, A., 1985. Cachectin/tumor necrosis factor stimulates collagenase and prostaglandin $\mathrm{E}_{2}$ production by human synovial cells and dermal fibroblasts. Journal of Experimental Medicine 162, 2163-2168.

Dombrowski, Y., Peric, M., Koglin, S., Kammerbauer, C., Goss, C., Anz, D., Simanski, M., Glaser, R., Harder, J., Hornung, V., et al., 2011. Cytosolic DNA triggers inflammasome activation in keratinocytes in psoriatic lesions. Science Translational Medicine 3, 82ra38.

Feldman, M., Maini, R.N., 2003. TNF defined as a therapeutic target for rheumatoid arthritis and other autoimmune diseases. Nature Medicine 9, 1245-1250.

Gabriel, S.E., 2001. The epidemiology of rheumatoid arthritis. Rheumatic Disease Clinics of North America 27, 269-281.
Galligan, C.L., Siminovitch, K.A., Keystone, E.C., Bykerk, V., Perez, O.D., Fish, E.N., 2010. Fibrocyte activation in rheumatoid arthritis. Rheumatology 49, 640-651.

Gartlehner, G., Hansen, R.A., Jonas, B.L., Thieda, P., Lohr, K.N., 2006. The comparative efficacy and safety of biologics for the treatment of rheumatoid arthritis: a systemic review and metaanalysis. The Journal of Rheumatology 33, 2398-2408.

Hegen, M., Keith Jr., J.C., Collins, M., Nickerson-Nutter, C.L., 2008. Utility of animal models for identification of potential therapeutics for rheumatoid arthritis. Annals of the Rheumatic Diseases 67, 1505-1515.

Holmdahl, R., Klareskog, L., Andersson, M., Hansen, C., 1986. High antibody response to autologous type II collagen is restricted to $\mathrm{H}-2 \mathrm{q}$. Immunogenetics 24, 84-89.

Hutamekalin, P., Saito, T., Yamaki, K., Mizutani, N., Brand, D.D., Waritani, T., Terato K., Yoshino, S., 2009. Collagen antibody-induced arthritis in mice: development of a new arthritogenic 5-clone cocktail of monoclonal anti-type II collagen antibodies. Journal of Immunological Methods 343, 49-55.

Iyer, S.S., Cheng, G., 2012. Role of interleukin 10 transcriptional regulation in inflammation and autoimmune disease. Critical Reviews in Immunology 32, 23-63.

Jo, E.K., 2010. Innate immunity to mycobacteria: vitamin D and autophagy. Cellular Microbiology 12, 1026-1035.

Kanda, N., Ishikawa, T., Kamata, M., Tada, Y., Watanabe, S., 2010. Increased serum leucine, leucine-37 levels in psoriasis: positive and negative feedback loops of leucine, leucine-37 and pro- or anti-inflammatory cytokines. Human Immunology $71,1161-1171$.

Mayer, M.L., Blohmke, C.J., Falsafi, R., Fjell, C.D., Madera, L., Turvey, S.E., Hancock, R.E., 2013. Rescue of dysfunctional autophagy attenuates hyperinflammatory responses from cystic fibrosis cells. Journal of Immunology 190, 1227-1238.

Molhoek, E.M., den Hertog, A.L., de Vries, A.M., Nazmi, K., Veerman, E.C., Hartgers, F.C., Yazdanbakhsh, M., Bikker, F.J., van der Kleij, D., 2009. Structure-function relationship of the human antimicrobial peptide LL-37 and LL-37 fragments in the modulation of TLR responses. Biological Chemistry 390, 295-303.

Mookherjee, N., Brown, K.L., Bowdish, D.M.E., Doria, S., Falsafi, R., Hokamp, K., Roche, F.M., Mu, R., Doho, G.H., Pistolic, J., et al., 2006a. Modulation of the TLR-mediated inflammatory response by the endogenous human host defense peptide LL-37. The Journal of Immunology 176, 2455-2464

Mookherjee, N., Wilson, H.L., Doria, S., Popowych, Y., Falsafi, R., Yu, J.J., Li, Y., Veatch, S., Roche, F.M., Brown, K.L., et al., 2006b. Bovine and human cathelicidin cationic host defense peptides similarly suppress transcriptional responses to bacterial lipopolysaccharide. Journal of Leukocyte Biology 80, 1563-1574.

Mookherjee, N., Hamill, P., Gardy, J., Blimkie, D., Falsafi, R., Chikatamarla, A., Arenillas, D.J., Doria, S., Kollmann, T.R., Hancock, R.E., 2009. Systems biology evaluation of immune responses induced by human host defence peptide LL-37 in mononuclear cells. Molecular BioSystems 5, 483-496.

Morioka, Y., Yamasaki, K., Leung, D., Gallo, R.L., 2008. Cathelicidin antimicrobial peptides inhibit hyaluronan-induced cytokine release and modulate chronic allergic dermatitis. Journal of Immunology 181, 3915-3922.

Nandakumar, K.S., Holmdahl, R., 2005. Efficient promotion of collagen antibody induced arthritis (CAIA) using four monoclonal antibodies specific for the major epitopes recognized in both collagen induced arthritis and rheumatoid arthritis. Journal of Immunological Methods 304, 126-136.

Nijnik, A., Madera, L., Ma, S., Waldbrook, M., Elliott, M.R., Easton, D.M., Mayer, M.L. Mullaly, S.C., Kindrachuk, J., Jenssen, H., et al., 2010. Synthetic cationic peptide IDR-1002 provides protection against bacterial infections through chemokine induction and enhanced leukocyte recruitment. Journal of Immunology 184 2539-2550.

Nishikawa, M., Myoui, A., Tomita, T., Takahi, K., Nampei, A., Yoshikawa, H., 2003. Prevention of the onset and progression of collagen-induced arthritis in rats by the potent p38 mitogen-activated protein kinase inhibitor FR167653. Arthritis and Rheumatism 48, 2670-2681.

Nizet, V., Ohtake, T., Lauth, X., Trowbridge, J., Rudisill, J., Dorschner, R.A., Pestonjamasp, V., Piraino, J., Huttner, K., Gallo, R.L., 2001. Innate antimicrobial peptide protects the skin from invasive bacterial infection. Nature 414, 454-457.

Pena, O.M., Afacan, N., Pistolic, J., Chen, C., Madera, L., Falsafi, R., Fjell, C.D., Hancock, R.E., 2013. Synthetic cationic peptide IDR-1018 modulates human macrophage differentiation. PLOS ONE 8, e52449.

Saklatvala, J., 1986. Tumour necrosis factor $\alpha$ stimulates resorption and inhibits synthesis of proteoglycan in cartilage. Nature 322, 547-549.

Scott, M.G., Dullaghan, E., Mookherjee, N., Glavas, N., Waldbrook, M., Thompson, A., Wang, A., Lee, K., Doria, S., Hamill, P., et al., 2007. An anti-infective peptide that selectively modulates the innate immune response. Nature Biotechnology 25 , 465-472.

Sun, J., Jia, Y., Li, R., Guo, J., Sun, X., Liu, Y., Li, Y., Yao, H., Liu, X., Zhao, J., et al., 2011. Altered influenza virus haemagglutinin (HA)-derived peptide is potent therapy for CIA by inducing Th1 to Th2 shift. Cellular \& Molecular Immunology 8, 348-358.

Tai, E.K., Wu, W.K., Wong, H.P., Lam, E.K., Yu, L., Cho, C.H., 2007. A new role for cathelicidin in ulcerative colitis in mice. Experimental Biology and Medicine (Maywood, NJ) 232, 799-808.

Torossian, A., Gurschi, E., Bals, R., Vassiliou, T., Wulf, H.F., Bauhofer, A., 2007. Effects of the antimicrobial peptide LL-37 and hyperthermic preconditioning in septic rats. Anesthesiology 107, 437-441.

Turner-Brannen, E., Choi, K.Y., Lippert, D.N., Cortens, J.P., Hancock, R.E., El-Gabalawy, H., Mookherjee, N., 2011. Modulation of interleukin-1beta-induced inflammatory responses by a synthetic cationic innate defence regulator peptide, IDR-1002, in synovial fibroblasts. Arthritis Research and Therapy 13, R129.

van der Does, A.M., Beekhuizen, H., Ravensbergen, B., Vos, T., Ottenhoff, T.H., van Dissel, J.T., Drijfhout, J.W., Hiemstra, P.S., Nibbering, P.H., 2010. LL-37 directs 
macrophage differentiation toward macrophages with a proinflammatory signature. Journal of Immunology 185, 1442-1449.

van Holten, J., Reedquist, K., Sattonet-Roche, P., Smeets, T.J., Plater-Zyberk, C., Vervoordeldonk, M.J., Tak, P.P., 2004. Treatment with recombinant interferon-beta reduces inflammation and slows cartilage destruction in the collagen-induced arthritis model of rheumatoid arthritis. Arthritis Research and Therapy 6, R239-R249.

Vandamme, D., Landuyt, B., Luyten, W., Schoofs, L., 2012. A comprehensive summary of LL-37, the factotum human cathelicidin peptide. Cellular Immunology 280, 22-35.
Wieczorek, M., Jenssen, H., Kindrachuk, J., Scott, W.R., Elliott, M., Hilpert, K., Cheng J.T., Hancock, R.E., Straus, S.K., 2010. Structural studies of a peptide with immune modulating and direct antimicrobial activity. Chemistry and Biology 17, 970-980.

Winthrop, K.L., 2006. Risk and prevention of tuberculosis and other serious opportunistic infections associated with the inhibition of tumor necrosis factor. Nature Clinical Practice Rheumatology 2, 602-610.

Yeung, A.T., Gellatly, S.L., Hancock, R.E., 2011. Multifunctional cationic host defence peptides and their clinical applications. Cellular and Molecular Life Sciences 68, 2161-2176. 